\title{
Congenital abnormality of the lower lid
}

\author{
J. L. AGGARWAL \\ Norfolk and Norwich Hospital
}

A 4-day-old baby girl had restricted movement of the left lower lid, giving the impression that the left eye was larger than the right. She was a full-term baby delivered by Caesarean section.

\section{Examination}

Movements of the left lower lid were restricted. There was a clear area of sclera between the cornea and lower lid and the lid seemed to be fixed to the orbital margin (Fig. I), and could not be pulled down as could the right lower lid (Fig. 2).

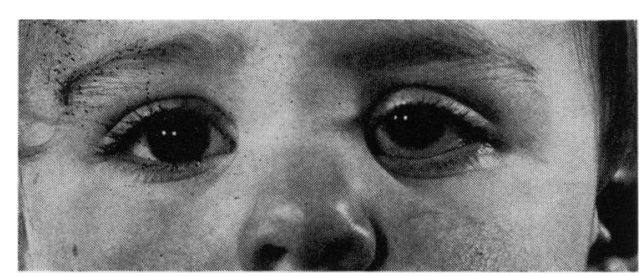

FIG. I Clear area of sclera is seen between the tethered left lower lid and the cornea

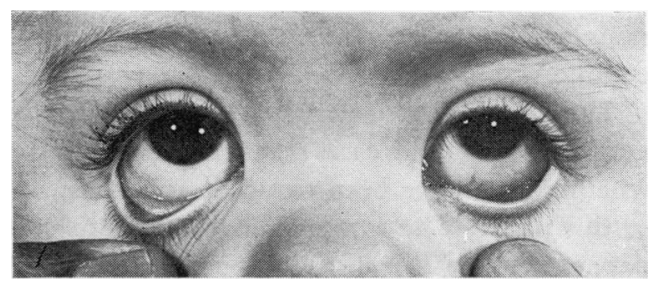

FIG. 2 Restricted mobility of left lower lid on traction

\section{Electromyography}

Direct stimulation of the facial nerve on the left showed that all groups of muscles were working normally.

\section{Surgery}

An incision was made into the lower fornix. The inferior rectus and inferior oblique muscles were identified. A thick band of fibrous tissue was found to stretch from the lower edge of the tarsal plate to the lower orbital margin. The band was divided and the lid freed. The conjunctival wound was sutured.

\section{Result}

Postoperatively there was an improvement in the cosmetic appearance, the lid being no longer tethered but freely mobile (Fig. 3).

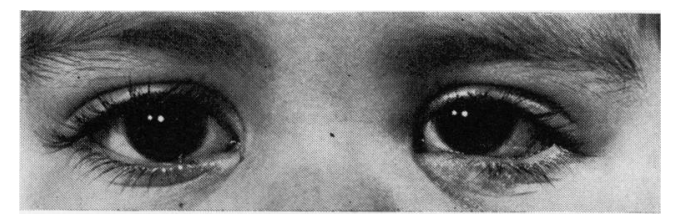

FIG. 3 Improvement in cosmetic appearance 